DOI: https://doi.org/10.33330/jurteksi.v7i2.933

Available online at http://jurnal.stmikroyal.ac.id/index.php/jurteksi

\title{
IMPLEMENTASI TEKNOLOGI FIREWALL SEBAGAI KEAMANAN SERVER DARI SYN FLOOD ATTACK
}

\author{
Sahren \\ ${ }^{1}$ Sistem Komputer, Sekolah Tinggi Manajemen Informatika dan Komputer Royal \\ email: sahren.one@gmail.com
}

\begin{abstract}
During the Covid-19 pandemic, the centralized academic information system is very vulnerable to various forms of attacks, such as SYN Flood, ICMP Flood, DoS, etc. This attack will cause the server to slow down, so that it takes a long time to access the application. For this reason, a method is needed so that server security is guaranteed. The method used is packet filtering firewall. The results obtained from this study can improve server security and capturing traffic that leads to the server. So this method can be used to increase security on the server.
\end{abstract}

Keywords: DoS; Firewall; ICMP Flood; Packet Filtering; SYN Flood; Server

Abstrak: Dimasa pandemi Covid-19 saat ini sistem informasi akademik secara terpusat sangat rawan terhadap berbagai bentuk serangan, seperti SYN Flood, ICMP Flood, DoS, dll. Serangan ini akan mengakibatkan server menjadi lambat, sehingga lama dalam mengakses aplikasi. Untuk itu, dibutuhkan suatu metode agar keamanan server lebih terjamin. Metode yang digunakan adalah packet filtering firewall. Hasil yang diperoleh dari penelitian ini dapat meningkatan kemanan server dan capturing traffic yang mengarah kepada server. Sehingga metode ini dapat digunakan untuk meningkatkan keamanan pada server.

Kata kunci: DoS; Firewall; ICMP Flood; Packet Filtering; SYN Flood; Server

\section{PENDAHULUAN}

Sistem informasi yang secara terpusat sangat rawan terhadap berbagai macam serangan seperti DoS SYN Flood dan lain sebagainya. Seorang penyerang akan menyerang sistem jaringan dengan maksud guna mengalahkan layanan keamanan pada fasilitas jaringan tersebut. Dengan mempertimbangkan fakta bahwa jaringan public pada awalnya dirancang untuk keterbukaan tanpa mempertimbangkan keamanan, jelas diikuti meningkatnya pula serangan cybercriminals dari tahun ketahuan[1].

Kelemahan dari protocol Transmission Control Protocol (TCP) terhadap
SYN Flood Attack kembali ditemukan oleh Bill Checwick dan Steve Bellowin, memberikan saran untuk mencegak serangan ini. Serangan SYN Flood jauh lebih efektif jika dibandingkan dengan penyerangan dengan teknik serangan $D e$ nial of Service (DoS) lainnya [2]. Serangan ini memanfaatkan kelemahan yang memang ada pada protocol Transmission Control Protocol/Internet (TCP/IP) ketika dirancang sejak awal [2]. Serangan SYN Flooding merupakan metode DoS yang mempengaruhi host yang menjalankan proses server TCP/IP [3]. Serangan ini akan membanjiri server dengan request palsu secara bertubi-tubi, mengeksploitasi dan menghabiskan sum- 
berdaya jaringan. Pada dasarnya ketika sebuah komputer yang terhubung ke pada suatu server maka akan terjadi yang disebut koneksi TCP Ke server. Dimana client mengirim SYNchronize ke server dan server akan mengenali acknowledge (ACK) request ini dengan mengirim balik SYN-ACK ke client dan client mengirim ACK maka koneksi akan terbentuk [4]. Proses hubungan ini juga dikenal dengan sebutan TCP Three Way Handshake. Namun, pada kasus SYN Flood kode yang seharusnya dikirim kembali oleh client pada fase terakhir, tidak dikirim kembali justru komputer membuat request baru kesemua port yang ada pada server. Akibatnya koneksi masih terbuka dan tidak bisa ditutup oleh server hal ini akan terjadi secara terus-menerus akan mengakibatkan server menjadi sangat sibuk [5]. Dengan besarnya dampak yang akan ditimbulkan oleh serangan SYN Flood maka diperlukan suatu metode untuk menjamin keamanan server, salah satunya adalah dengan memanfaatkan metode packet filtering firewall.

Firewall disini suatu mekanisme keamanan mendasar yang digunakan untuk jaringan komputer. Baik yang bersifat open source hingga komersil [6]. Firewall dapat untuk memperkuat dan melindungi sumberdaya dalam jaringan dengan menolak setiap akses berbahaya dari luar. Firewall digolongkan menjadi dua yaitu: packet filtering dan aplikasi firewall [7]. Kinerja dari firewall menjadi perhatian utama dari sistem keamanan dikarenakan penurunan kinerjanya bisa menghancurkan integritas data bahkan ketersediaan layanan dapat terganggu [7]. Packet filtering merupakan elemen yang terdapat pada firewall yang akan menganalisa dan mengontrol setiap paket data yang masuk maupun keluar pada lapisan network access, network dan transfort baik lewat media fisik maupun non fisik [8]. Saat packet filtering terpasang setiap pengguna atau penyerang dalam jaringan tidak akan menyadarinya kecuali pada saat firewall menolak akses atau paket data yang dikirimnya [9].

Didalam rangkaian tugasnya akan tersusun dalam bentuk tabel filtrasi, yang merupakan konfigurasi default sistem, yang terdiri dari 3 chain yaitu: INPUT, FORWARD, dan OUTPUT [10]. Fungsi dari packet filtering dapat dianalogikan sebagai penjaga kemanan [8]. Menyediakan berbagai persyaratan keamanan seperti kualitas dan ketersediaan layanan informasi yang diperlukan [10]

Beberapa penelitian terdahulu telah banyak dilakukan berkaitan dengan metode serangan Danial of Service (DoS) SYN Flood, analisa dampak, deteksi serangan maupun tindakan pencegahan yang dapat dilakukan. [1] Melakukan penelitian tentang metode pertahanan web server terhadap Distributed Slow HTTP DoS Attack. [2] Melakukan penelitian sebuah pendekatan untuk mengurangi efek serangan DDoS TCP SYN Flood. [3] Melakukan penelitian tentang deteksi SYN Flood berdasarkan Bayes Estimator pada jaringan MANET. [4] Melakukan penelitian mengenai pengujian sistem keamanan jaringan melalui serangan DoS. [5] Melakukan penelitian pendeteksian serangan $S Y N$ Flood pada jaringan cloud computing menggunakan dukungan vector machine. [8] Melakukan sebuah penelitian untuk pengembangan model optimalisasi firewall menggunakan packet filtering. [10] Melakukan penelitian optimalisasi dan implementasi set aturan iptables di linux.

Tujuan pada penelitian ini adalah menggunakan metode packet filtering 
DOI: https://doi.org/10.33330/jurteksi.v7i2.933

Available online at http://jurnal.stmikroyal.ac.id/index.php/jurteksi

firewall untuk meningkatkan keamanan server di Sekolah Tinggi Manajemen Informatika (STMIK) Royal kisaran sehingga keamanannya lebih terjamin.

\section{METODE}

Pada bagian ini menjelaskan mengenai tahapan-tahapan sistematis yang dilakukan oleh penulis dalam melakukan penelitian untuk mengimplementasikan teknologi firewall sebagai suatu sistem keamanan guna mengatasi SYN Flood Attack. Adapun tahapan proses pembangunan sistem dan tahapan proses pada metode firewall packet filtering yang digunakan dapat di lihat pada gambar 1 berikut ini.

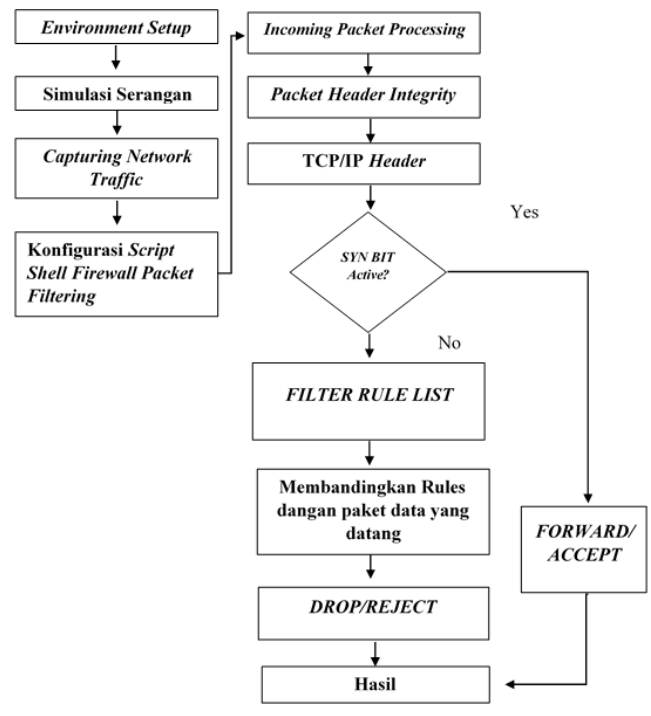

Gambar 1. Tahapan Penelitian

Berdasarkan tahapan penelitian yang terdapat pada gambar 1. Diuraiakan tahapan-tahapannya sebagai berikut:

Pertama Simulasi Serangan. Pada tahapan ini akan dilakukan percobaan serangan DoS SYN Flood pada server yang belum dipasang sistem kemanan firewall. Serangan akan dilakukan dengan mengirim sejumlah paket data ke dalam server secara terus menerus sehingga kinerja server akan terganggu di karenakan habisnya sumberdaya yang ada. Untuk melakukan simulasi serangan ini dapat di lakukan dengan menggunakan tools Hping3. Setelah dilakukannya serangan maka akan di analisa traffic yang mengarah pada server.

Kedua Konfigurasi Script Shell Firewall Tahap penulisan script shell ini adalah tahapan konfigurasi firewall packet filtering pada server dimana penulisan script shell ini dilakukan pada tools iptables. Konfigurasi yang di lakukan adalah untuk meningkatkan kemanan pada server dengan membuat rules atau aturan-aturan untuk memfilter setiap paket data yang masuk maupun keluar. Pada tahapan ini setiap paket akan disaring, paket yang masuk dan keluar harus sesuai dengan aturan. Tahapan pertama adalah mengekstrak IP Header dan melakukan pemerikasaan protocol TCP. Jika bit paket telah sesuai maka paket akan langsung di izinkan (FORWARD atau ACCEPT). Sedangkan paket yang tidak sesuai sistem akan membandingkan paket dengan aturan yang telah dibuat. Apabila protokol yang masuk sama akan diperiksa pada alamat tujuan, alamat sumber, port sumber dan port tujuan. Setelah itu akan diputuskan apa yang harus di lakukan dengan paket tersebut apakah di DROP ataupun di REJECT. Berikut sintaks penulisan rule difirewall dengan iptables.

\section{HASIL DAN PEMBAHASAN}

Didalam sebuah layanan jaringan terpusat terdapat layanan-layanan penting seperti $W E B$ SSH dan lain-lain, layanan tersebut memiliki jalur-jalur atau portport tertentu seperti pada $W E B$ dengan port 80 dan SSH dengan port 22. Port- 
port ini lah yang menjadi jalan masuk untuk melakukan koneksi dan juga dimanfaatkan sebagai jalur serangan dengan membanjiri port-port tersebut dengan banyak request. Dalam penelitian ini serangan akan dilakukan dengan menggunakan tools hping3.

Percobaan menggunakan satu komputer sebagai komputer server, dengan ipaddress 192.168.100.2 dan satu komputer sebagai penetration testing dengan ipaddress 192.168.100.100. Adapun topologinya adalah sebagai berikut:

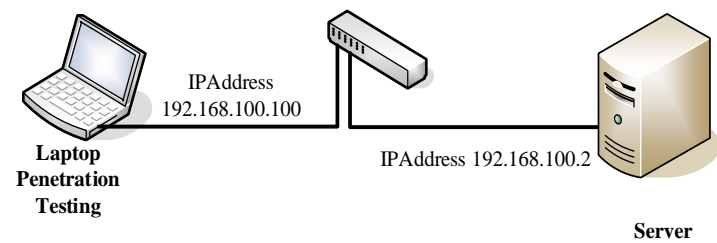

Gambar 2. Topologi Awal

Pada gambar 2 memperlihatkan bahwa koneksi antara laptop penetration testing dan komputer server di lakukan secara langsung tanpa ada dinding keamanan yang dilewati terlebih dahulu. Hal ini mengakibakan tidak adanya penyaringan terhadap lalu lintas data yang lewat. Sedangkan pada gambar 3 dapat kita lihat bahwa hubungan antara penetration testing dengan komputer server sudah dibatasi oleh firewall sehingga lalu lintas data yang masuk akan di cek atau di filter terlebih dahulu.

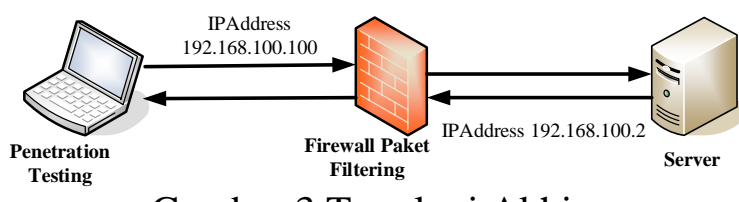

Gambar 3 Topologi Akhir

Serangan dengan mode Flooding data pada komputer server dijalankan dengan menjalankan command pada tools hping3 yaitu hping3 -flood $-S$-p 80 192.168.100.2 Setelah dilakukan serangan pada komputer server akan di lakukan analisa lalu lintas data dengan menggunakan tools wireshark. Dalam simulasi serangan ini komputer server akan merespon paket $S Y N$ dan mengirimkan kembali SYN flags ACK, akan tetapi komputer penyerang tidak merespon untuk memenuhi syarat three way handshake dengan mengirim ACK, tetapi mengirim flags RST sehingga koneksi akan setengah terbuka. Seperti yang ditampilkan pada gambar 4. Ketika koneksi seperti itu dibuat dalam beberapa detik akan mengakibatkan sumberdaya proses akan habis dalam waktu singkat.

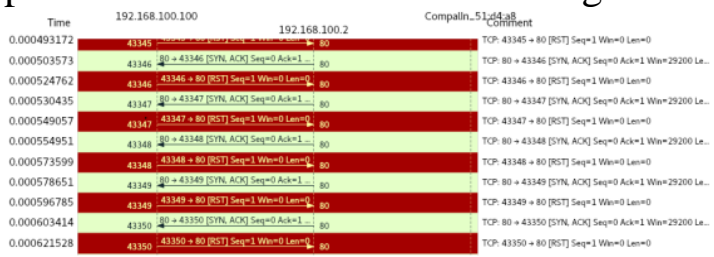

Gambar 4. Flowgraph Saat Ada

Serangan Sebelum Ada Firewall

Untuk pertahanan dari serangan SYN Flood dengan melakukan konfigurasi firewall packet filtering pada server dengan menuliskan script iptables dan dapat dilakukan pengecekan yang akan menghasilkan output seperti pada gambar 5 .

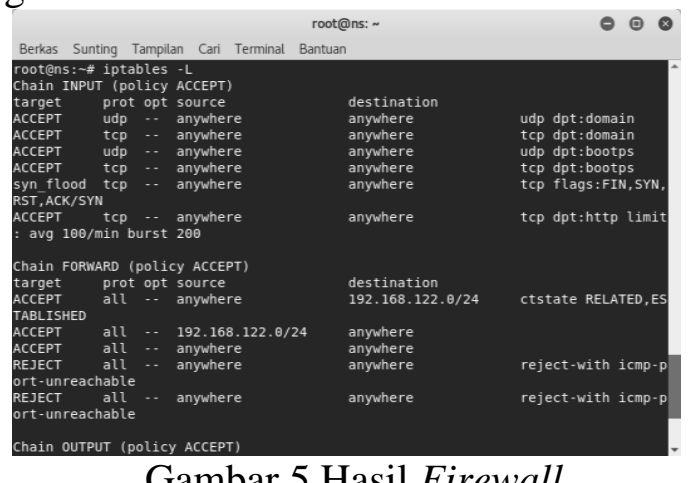

Gambar 5 Hasil Firewall

Setelah konfigurasi firewall dilakukan dengan menambahkan rules maka di lakukann recapture packet menggunakan wireshak sebagai test bahwa script atau rule yang ditambahkan telah bekerja dan untuk memperoleh hasil dari percobaan yang telah dilakukan. 
DOI: https://doi.org/10.33330/jurteksi.v7i2.933

Available online at http://jurnal.stmikroyal.ac.id/index.php/jurteksi

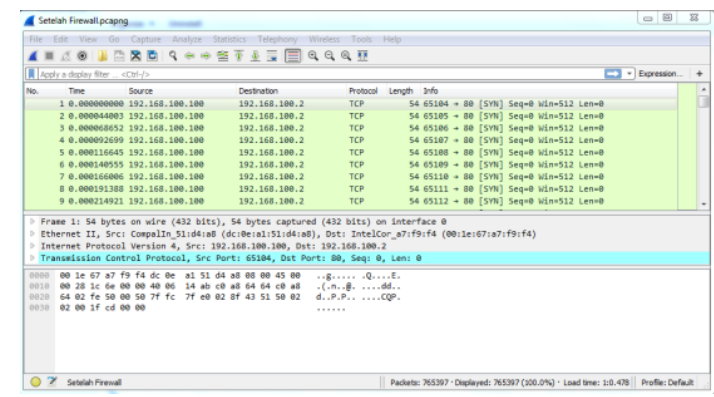

Gambar 6 Capturing Traffic

Gambar 6 merupakan hasil capturing pada traffic jaringan menuju server.

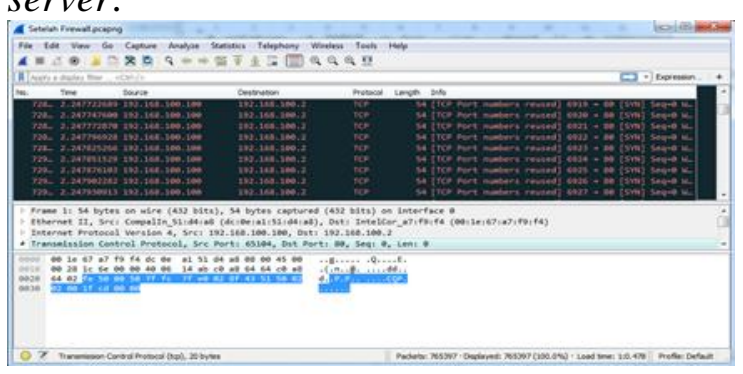

Gambar 7 Conection Reused

Pada gambar 7 dapat dilihat koneksi yang datang ke server secara terus menerus tidak dapat masuk ke server dikarenakan telah di lakukan filter terhadap packet yang akan masuk.

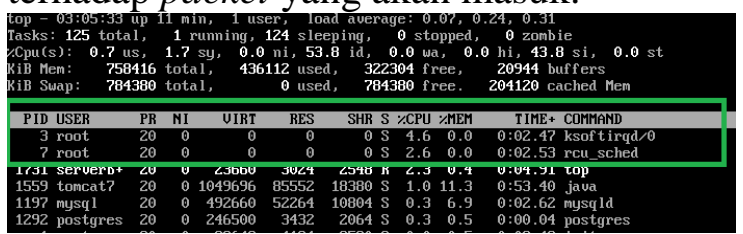

Gambar 8 Hasil Monitoring Proses

Pada gambar 8 merupakan tampilan proses yang berjalan dan penggunaan resource yang selama terjadi serangan ketika server sudah terpasang sistem keamanan dengan teknologi firewall.

Dalam penelitian ini, di uji kemampuan dari firewall packet filtering ketika terjadi eksploitasi terhadap server dan bertahan dari serangan yang terjadi. Untuk menentukan apakah sebuah lalu lintas jaringan sah atau tidak, firewall bergantung pada set aturan yang telah ditentukan oleh administrastor jaringan atau sistem untuk mengambil keputusan akhir yaitu mengizinkan atau menolah koneksi yang ada. Berdasarkan uji coba dan analisa traffic jaringan yang di lakukan terlihat perbedaan sebelum dan sesudah firewall di konfigurasi pada server ketika terjadi serangan sebagaimana terlihat pada hasil flowgraph pada gambar 4 dan gambar 7 . Pada monitoring penggunaan cpu saat serangan sedang terjadi dengan memasang firewall mampu menurunkan usage cpu $46 \%$ hingga turun menjadi 4,6 $\%$.

\section{SIMPULAN}

Berdasarkan hasil yang diperoleh dari penelitian ini dapat meningkatan kemanan server dilihat dari capturing traffic yang mengarah kepada server dan monitoring terhapat proses resource $\mathrm{CPU}$ saat terjadi serangan mampu menurunkan usage cpu $46 \%$ hingga turun menjadi 4,6 $\%$. Dengan mampunya firewall packet filtering menjaga penggunaan sumberdaya CPU pada server tetap rendah dan memfilter koneksi yang tidak sah. Maka dapat disimpulkan bahwa dengan metode ini dapat menjaga aspek ketersediaan atau avability. Sehingga metode ini dapat digunakan untuk meningkatkan keamanan pada server.

\section{DAFTAR PUSTAKA}

[1] M. Arman, "Metode Pertahanan Web Server Terhadap Distributed Slow HTTP DoS Attack," JATISI (Jurnal Tek. Inform. dan Sist. Informasi), vol. 7, no. 1, pp. 56- 
70, 2020, doi:

10.35957/jatisi.v7i1.284.

[2] M. Bogdanoski, A. Toshevski, D. Bogatinov, and M. Bogdanoski, "A novel approach for mitigating the effects of the TCP SYN flood DDoS attacks," World J. Model. Simul., vol. 12, no. 3, pp. 217-230, 2016.

[3] K. Hussain, S. J. Hussain, N. Z. Jhanjhi, and M. Humayun, " $S Y N$ flood attack detection based on bayes estimator (SFADBE) for MANET," 2019 Int. Conf. Comput. Inf. Sci. ICCIS 2019, pp. 1-4, 2019, doi: 10.1109/ICCISci.2019.8716416.

[4] A. Maraj, G. Jakupi, E. Rogova, and X. Grajqevci, "Testing of network security systems through DoS attacks," 2017 6th Mediterr. Conf. Embed. Comput. MECO 2017 - Incl. ECYPS 2017, Proc., no. June, pp. 11-15, 2017, doi: 10.1109/MECO.2017.7977239.

[5] Z. Mašetić, D. Kečo, N. Doğru, and K. Hajdarević, "SYN Flood Attack Detection in Cloud Computing Using Support Vector Machine," TEM J., vol. 6, no. 4, pp. 752-759, 2017, doi: 10.18421/TEM64-15.

[6] C. Diekmann, L. Hupel, J.
Michaelis, M. Haslbeck, and G. Carle, "Verified iptables Firewall Analysis and Verification," $J$. Autom. Reason., vol. 61, no. 1-4, pp. 191-242, 2018, doi: 10.1007/s10817-017-9445-1.

[7] P. S. Kadam, "Adaptive Packet Filtering Techniques for Linux Firewall," vol. 3, pp. 171-174, 2017.

[8] M. Thant, K. M. Thu, K. Z. Ye, and S. T. T. Sin, "Development of firewall optimization model using by packet filter," Proc. - 2016 UKSim-AMSS 18th Int. Conf. Comput. Model. Simulation, UKSim 2016, pp. 273-278, 2016, doi: 10.1109/UKSim.2016.45.

[9] A. A. Ali, S. M. Darwish, and S. K. Guirguis, "An Approach for Improving Performance of a Packet Filtering Firewall Based on Fuzzy Petri Net," J. Adv. Comput. Networks, vol. 3, no. 1, pp. 67-74, 2015, doi: 10.7763/JACN.2015.V3.144.

[10] L. Xuan and P. Wu, "The Optimization and Implementation of Iptables Rules Set on Linux," 2015 2nd Int. Conf. Inf. Sci. Control Eng., pp. 988-991, 2015, doi: 10.1109/ICISCE.2015.223. 